\title{
Neuroendocrine effects of diuretics in heart failure
}

\author{
P A van Zwieten
}

Chronic congestive heart failure (CHF) is known to be associated with two main types of compensatory mechanisms: ventricular dilatation, leading to left ventricular hypertrophy; and neuroendocrine mechanisms.

Both haemodynamic and neuroendocrine mechanisms provide inotropic support for the decompensated heart, but in the long-term they can introduce an important risk. To prevent such adverse structural and functional effects, the magnitude of both ventricular dilatation and sympathetic activation are subject to limiting and regulatory mechanisms. ${ }^{1-3}$ I shall restrict the discussion of the compensatory mechanisms and their regulation to the neuroendocrine changes associated with chronic CHF.

Diuretics, the mainstay of the drug treatment of CHF, may be expected to interact with the neuroendocrine processes in a complex manner with both advantages and disadvantages. This interaction is the subject of my survey.

\section{Neuroendocrine changes}

A reduction in cardiac output, as in chronic $\mathrm{CHF}$, will trigger two main mechanisms to maintain systemic perfusion pressure: peripheral vasoconstriction; and the retention of sodium and water. Both mechanisms are produced by the interplay of haemodynamic and neuroendocrine factors (fig 1)..$^{1-8}$

The sympathetic system is activated at an early stage of the disease when ventricular dilatation begins and in many cases before the development of overt symptoms of CHF.

The renin-angiotensin-aldosterone system is usually activated once symptoms develop and also as a result of the treatment with diuretics. When systemic perfusion is threatened, as in the terminal stages of the disease, vasopressin will be released. As well as these circulating factors $\mathrm{CHF}$ is accompanied by an enhanced activity of certain local vasoconstrictors such as endothelin. Atrial natriuretic peptide is released from both the right and left cardiac atria as a result of stretch brought about by CHF. Atrial natriuretic peptide should be considered as an endogenous diuretic and vasodilator and hence it counteracts the effects of these vasoconstrictors and that of sodium retention.

Long-term CHF will lead to attenuation of the release of both atrial natriuretic peptide and endothelium derived relaxing factor. ${ }^{9}$ Accordingly, there will be less vasodilator activity to oppose the actions of the vasoconstrictors.
With respect to these various systems subject to activation in CHF the following remarks may be made.

\section{SYMPATHETIC NERVOUS SYSTEM}

Activation of the sympathetic nervous system is characteristic for CHF and there seems to be a correlation between the concentration of plasma noradrenaline and prognosis. A higher plasma noradrenaline concentration implies a less favourable prognosis. ${ }^{10}$ High plasma noradrenaline concentrations are responsible for the well known down regulation of myocardial $\beta$ adrenoceptors, ${ }^{11}{ }^{12}$ which explains the poor response of the chronically failing heart to catecholamines and $\beta$ adrenoceptor stimulants. The activation of the sympathetic nervous system is a consistent finding in patients with CHF. Conversely, successful therapeutic intervention usually leads to a less pronounced sympathetic nervous system activation, as reflected by low plasma noradrenaline concentrations.

RENIN-ANGIOTENSIN-ALDOSTERONE SYSTEM The activation of the renin-angiotensinaldosterone system is responsible for the sodium and fluid retention in CHF. Furthermore there exists a relevant mutual interaction between various components of the renin-angiotensin-aldosterone system and the sympathetic nervous system, for instance at the level of the sympathetic ganglia, postsynaptic $a$ adrenoceptors, and presynaptic angiotensin II receptors (fig 2)..$^{1-8}$

The activation of the renin-angiotensinaldosterone system - as reflected by high plasma renin activity, angiotensin II, and aldosterone concentrations - is less consistent than that of the sympathetic nervous system, with con-siderable variations between individual patients. ${ }^{13}$

Plasma noradrenaline concentrations give a somewhat better indication of the severity of the disease and its prognosis than plasma renin activity or plasma aldosterone concentrations. As discussed later treatment with diuretics is an important additional cause of the acti-vation of the renin-angiotensin-aldosterone system.

\section{VASOPRESSIN}

The enhanced release of vasopressin is triggered by the threatening of impaired systemic perfusion. ${ }^{1-8}$ Vasopressin will cause an antidiuretic effect and peripheral vasoconstriction. It therefore contributes to both the retention of sodium and to peripheral vasoconstriction. The increase in vasopressin is variable and its 
Figure 1 Stimulation of the sympathetic nervous system (SNS) and the renin-angiotensinaldosterone system (RAAS) in CHF. Reflex activation of the SNS causes tachycardia and enhanced contractility through $\beta_{1}$ receptor stimulation.

Vasoconstriction, induced by postsynaptic $a_{1}$ and $a_{2}$ adrenoceptor stimulation is detrimental, as it raises total peripheral resistance (TPR) and, hence cardiac afterload. The RAAS is stimulated through $\beta_{1}$ adrenoceptors of the SNS and also by the impaired pump function of the heart, which leads to the retention of sodium and water. Stimulation of the RAAS causes a further rise in cardiac afterload. The enhanced release of aldosterone causes a further increase in the retention of sodium and water and thus increases the plasma volume and cardiac preload. NA, noradrenaline.

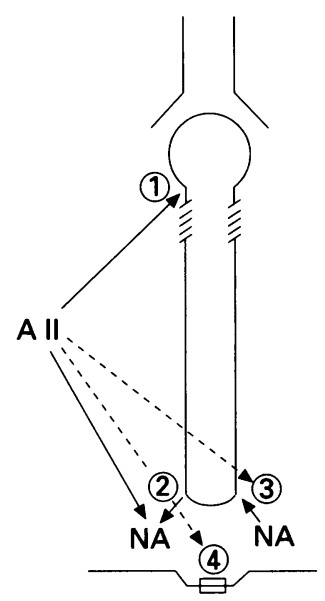

Figure 2 Potential interference of angiotensin II (A II) with sympathetic nervous activity and its effects. Schematic presentation of postganglionic sympathetic neurone. (1) Ganglionic stimulation; (2) enhanced release of noradrenaline NA) (tyramine like activity); (3) inhibition of the noradrinaline reuptake the noradrenaline reup
into the neurone; (4) sensitisation of

postjunctional $a_{2}$ adrenoceptors.

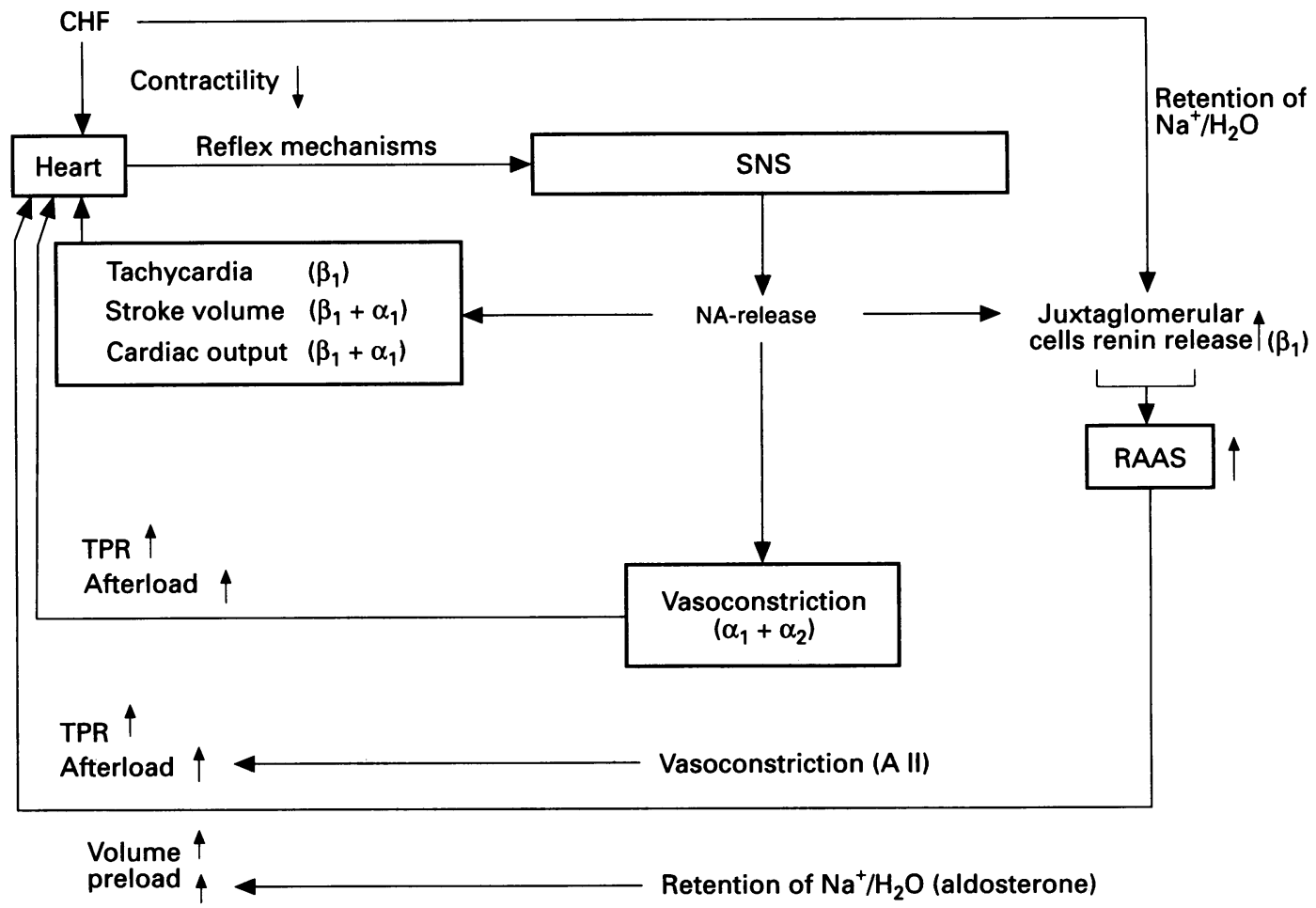

role in CHF is less certain than that of the sympathetic nervous system and the reninangiotensin-aldosterone system.

\section{ATRIAL NATRIURETIC PEPTIDE}

The atrial natriuretic peptide is the most powerful functional antagonist of the sequelae of the stimulated sympathetic nervous system and renin-angiotensin-aldosterone system. Atrial stretch as in CHF is the most direct trigger mechanism for release of atrial natriuretic peptide. The degree of increase of atrial natriuretic peptide concentration seems to run parallel to the severity of the disease. Conversely, successful therapeutic intervention has been shown to be followed by a decrease in the raised atrial natriuretic peptide concentrations. ${ }^{14} 15$

\section{DOPAMINE AND PROSTAGLANDINS}

Dopamine and various prostaglandins are also subject to enhanced release in CHF. Their vasodilator and renal (diuretic) effects may contribute as compensatory factors similar to those of atrial natriuretic peptide, but their importance is less well documented.

Finally, the antagonistic activities of atrial natriuretic peptide and other factors are insufficient to compensate for the peripheral vasoconstriction and sodium retention in advanced chronic CHF. ${ }^{1-8}$

\section{Effects of diuretics}

The use of diuretics in CHF is usually limited to the powerful loop diuretics, such as frusemide, bumetanide, and piretanide. The thiazide diuretics are usually insufficiently active and their use is restricted to the treatment of hypertension. The haemodynamic effects of loop diuretics in the treatment of $\mathrm{CHF}$ are varied. Owing to the loss of $\mathrm{Na}^{+}$ ions, $\mathrm{Cl}^{-}$ions, and water the circulating plasma volume is reduced, thus causing a reduction of cardiac preload. ${ }^{16-19}$ Indirect evidence also points towards a reduction in cardiac afterload, which is attributed to the fact that the vasoconstrictor activity of endogenous catecholamines is diminished at a low sodium concentration. Heart rate is not directly affected by the diuretics, although it may decrease as a result of low compensatory SNS activation, associated with successful therapeutic intervention.

The influence of diuretics on the neuroendocrine derangements, although of vital importance, has not been studied on a sufficiently large scale. From the limited data available it may be concluded that the influence of diuretics on neuroendocrine changes in CHF is complex: (a) successful therapeutic intervention as a whole will lead to a decrease in the hyperactivity of the sympathetic nervous system, as reflected by a reduction of the increase in plasma noradrenaline concentration $^{16-19}$; (b) similarly, the increased atrial natriuretic peptide concentration will be reduced, thus reflecting the improvement in the circulatory derangement ${ }^{14}{ }^{15}$; (c) by contrast, diuretic treatment will cause a further stimulation of the renin-angiotensin-aldosterone system, despite the therapeutic improvement: Patients chronically treated with loop diuretics will consistently show increased plasma renin activity, as well as angiotensin II and aldosteron concentrations. Accordingly, the favourable haemodynamic effects of the diuretics are lessened by the high concentrations of angiotensin II, whereas the potassium losing effects of the diuretics are enhanced. Both noxious effects are counteracted by angiotensin converting enzyme (ACE) inhibitors, which will reduce the rise in plasma angiotensin II; (d) acute intravenous 
treatment of patients with severe chronic heart failure with frusemide may be associated with sympathetic excitation shown by increases in plasma noradrenaline, heart rate, blood pressure, and vascular resistance. ${ }^{19}$ Probably as a result of the important interaction between the sympathetic nervous system and the renin-angiotensin-aldosterone system there is also a rise in plasma renin activity. This sympathetic activation precedes the diuretic action of frusemide and is associated with an acute deterioration of left ventricular pump function in these patients. The pressor response to frusemide is counteracted by pretreatment with an ACE inhibitor. ${ }^{20}$

Notwithstanding the widespread use of diuretic agents in CHF and their beneficial influence in the short-term, many questions continue to be raised with respect to their therapeutic value in the long term. Their potentially noxious effects on the reninangiotensin-aldosterone system are a source of potential problems. Adequate, large scale clinical trials on this subject have not been performed so far.

Considering future perspectives it seems of interest to consider the potential value of atrial natriuretic peptide, the body's natural diuretic, in the treatment of chronic CHF. In contrast with loop and thiazide diuretics it displays strong natriuretic activity that is accompanied by a reduction of plasma renin activity and of plasma angiotensin II concentrations.

It therefore seems important to study endopeptidase inhibitors, which will cause a rise in atrial natriuretic peptide, in the treatment of CHF. ${ }^{51}$

1 Packer M. Role of the sympathetic system in chronic hear failure: a historical and philosophical perspective. Circulation 1990;82:I-1-6.

2 Francis GS, Goldsmith SR, Levine TB, Olivari MT, Cohn
JN. The neurohumoral axis in congestive heart failure. Ann Intern Med 1984;101:370-7.

3 Francis GS. Neurohumoral mechanisms involved in congestive heart failure. Am $\mathcal{f}$ Cardiol 1985;55(suppl 2): 15A-21A.

4 Packer $M$. Neurohumoral interactions and adaptations in congestive heart failure. Circulation 1988;77:721-30.

5 Packer M. Pathophysiology of chronic heart failure. Lancet 1992;340:88-92.

6 Creager MA, Faxon DP, Cutter SS, Kohlman O, Ryan TJ, Garras H. Contribution of vasopressin to vasoconstriction in patients with congestive heart failure: comparison with the renin-angiotensin system and the sympathetic nervous system. $\mathcal{F}$ Am Coll Cardiol 1986;7:758-65.

7 Eiskjaer H, Bagger JP, Danielsen H. Mechanisms of sodium retention in heart failure: relation to the reninsodium retention in heart failure: relation to the renin-
angiotensin-aldosterone system. Am $\mathcal{F}$ Physiol 1991;260: F883-9.

8 Ritz E, Fliser D. The kidney in congestive heart failure Eur Heart $f$ 1991;12:(suppl C): 14-20.

9 Cody RJ, Atlas SA, Laragh JH. Atrial natriuretic factor in normal subjects and heart failure patients: plasma levels and renal, hormonal and hemodynamic responses to peptide infusion. $\mathcal{F}$ Clin Invest 1986;78:1362-74

10 Cohn JN, Levine TB, Olivari MT, Garbey V, Lura D Francis GS, et al. Plasma norepinephrine as a guide to prognosis in patients with chronic congestive heart failure. N Engl ₹ Med 1984;311:819-23.

11 Bristow MR, Herhberger RE, Port JD. $\beta$-Adrenergic pathways in non-failing and failing human ventricular myocardium. Circulation 1990;82 (suppl I):12-25.

12 Neuman J, Schmitz W, Scholz $\mathrm{H}$, von Meyerinck $L$ Doring V, Kalman $P$. Increase in myocardial $G_{i}$ proteins Doring V, Kalman P. Increase in myoca

13 Ferrari R, Menotti A, Gei P, de Giuli F, Tabaglio A Anand I. Hemodynamic and hormonal changes in chronic heart failure: effect of ACE-inhibition. $\mathcal{F}$ Cardiovasc Pharmacol 1992;20(suppl B):S49-59.

14 Raine A, Erne P, Burgisser E. Atrial natriuretic peptide and atrial pressure in patients with congestive heart failure. $N$ Engl f Med 1986;315:533-7.

15 Ogaea $\mathrm{K}$, Ito $\mathrm{T}$, Mashimoto $\mathrm{H}$. Plasma atrial natriuretic factor in congestive heart failure. Lancet 1986;i:106-9.

16 Van Zwieten PA. Comparative mechanisms of diuretic drugs in hypertension. Eur Heart $\mathcal{f}$ 1992;13(suppl G): $2-4$.

17 Sinoway L, Minotti J, Musch T. Enhanced metabolic vasodilatation secondary to diuretic therapy in decompensated congestive heart failure secondary to coronary pensated congestive heart failure secondary to

18 Francis GS, Benedict C, Johnstone DE. Comparison of neuroendocrine activation in patients with left ventricular neuroendocrine activation in patients with left ventricular
dysfunction with and without congestive heart failure. dysfunction with and without
Circulation 1990;82:1724-9.

19 Francis GS, Siegel RM, Goldsmith SR, Olivari MT Levine TB, Cohn JN. Acute vasoconstrictor response to intravenous furosemide in patients with chronic congestive heart failure. Activation of the neurohumoral axis. Ann Intern Med 1985;103:1-6.

20 Goldsmith SR, Francis G, Cohn JN. Attenuation of the pressor response to intravenous furosemide by
angiotensin converting enzyme inhibition in congestive heart failure. Am $\mathcal{F}$ Cardiol 1989;64:1382-5.

21 Packer M. Treatment of chronic heart failure. Lancet 1992;340:92-5. 